Irving, M.A.; Conti, B.R.; Rodrigues, C.; Moraes, E.; Mattos, F. Rede TAPIS: uma iniciativa para ampliar a reflexão sobre áreas protegidas, turismo e inclusão social. Anais do VIII Congresso Nacional de Ecoturismo e do IV Encontro Interdisciplinar de Ecoturismo em Unidades de Conservação. Revista Brasileira de Ecoturismo, São Paulo, v.4, n.4, 2011, p. 504.

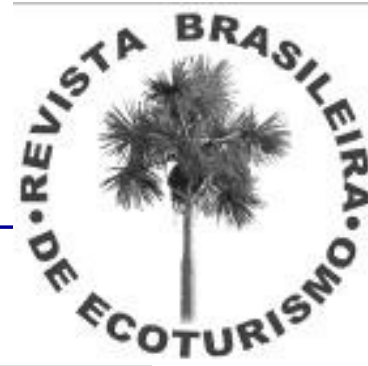

\title{
REDE TAPIS: UMA INICIATIVA PARA AMPLIAR A REFLEXÃO SOBRE ÁREAS PROTEGIDAS, TURISMO E INCLUSÃO SOCIAL
}

\section{Marta de Azevedo Irving*, Bruna Ranção Conti*, Camila Rodrigues*, Edilaine Moraes*, Flávia Mattos*}

*Universidade Federal do Rio de Janeiro

E-mails: marta.irving@mls.com.br, bruna-conti@hotmail.com, camirural@gmail.com, edilainerumos@yahoo.com.br, flaviamattos40@hotmail.com

O planejamento turístico em áreas protegidas, no Brasil, tem sido, historicamente, influenciado pela lógica do mercado e, freqüentemente, ocorre dissociado de uma perspectiva estratégica, que considere também o compromisso de inclusão social. Tendo em vista esta demanda, a potencialidade dessas áreas como inspiração para novas práticas de planejamento turístico e, a necessidade de reflexão sobre o tema, intercâmbio e estabelecimento de parcerias capazes de integrar os elementos éticos e sociais ao processo, foi concebida, em 2006, a Rede de Áreas Protegidas, Turismo e Inclusão Social (Rede TAPIS), vinculada ao Grupo de Pesquisa em Governança, Biodiversidade, Áreas Protegidas e Inclusão Social (GAPIS/Lattes CNPq). Com esta perspectiva, o objetivo deste trabalho é descrever e discutir o processo de formação da Rede, alguns dos resultados alcançados no período de 2007 a 2011 e, os desafios a serem enfrentados para que iniciativas deste tipo possam apoiar a integração entre diferentes segmentos da sociedade, e ter rebatimentos em políticas públicas de proteção da natureza e turismo. A Rede TAPIS foi delineada a partir de diretrizes e princípios norteadores de uma nova concepção de turismo e se estruturou com base na adesão voluntária de parceiros institucionais. Neste processo, a Rede tem desenvolvido ações de difusão da informação, realização de eventos nacionais e internacionais e capacitação de recursos humanos. Mas são inúmeras as dificuldades enfrentadas para que estes esforços possam efetivamente impactar a integração de políticas públicas. E essas dificuldades dizem respeito, principalmente, aos esforços necessários para a mobilização permanente dos membros da Rede, à captação de recursos para o desenvolvimento de projetos coletivos, à demanda de balizamento conceitual com relação aos seus princípios e valores norteadores, e à sensibilização dos órgãos públicos sobre a relevância do processo.

Palavras-chave: Rede, Áreas Protegidas, Turismo, Inclusão Social. 